\title{
PENGARUH KUALITAS PRODUK DAN JASA PADA EKUITAS PELANGGAN DI COFFEE TOFFEE INDONESIA
}

\author{
Sri Widyastuti ${ }^{1}$, Zainuddin ${ }^{2}$ \\ Faculty of Economic and Business, University of Pancasila \\ e-mail: widyastuti_iis@yahoo.co.id
}

\begin{abstract}
A failure in business is a valuable experience so that Coffee Toffee must be able to maintain its customer equity to make Coffee Toffee as one of the biggest and the best coffee shop in Indonesia. This study is to acknowledge the influence of product quality and service quality as a whole and partially on the customer equity. The analysis methods used in this study are statistic descriptive and verificative. Multiple Regression Test uses the assistance of SPSS version 2.0 program. The results of this study show that both product quality and service quality influence the customer equity since product and service quality are important factors to buildcustomer equity in culinary business. Product quality influences positively and significantly on the customer equity since product quality from customer reaction is qualified but the service quality does not significantly influence the customer equity because Coffee Toffee stand uses self service concept so that the communication level between customers and employees is low.
\end{abstract}

Keywords: Product Quality, Service Quality, Customer Equity

\begin{abstract}
Abstrak
Kegagalan bisnis merupakan pengalaman berharga, sehingga Coffee Toffee harus mampu mempertahankan ekuitas pelanggannya yang sangat penting dalam menjaga sustainability gerai Coffee Toffee, agar dapat menjadi salah satu Coffee Shop terbesar dan terbaik di Indonesia. Penelitian ini bertujuan untuk mengetahui pengaruh kualitas produk dan kualitas layanan secara bersama-sama maupun parsial terhadap ekuitas pelanggan. Metode analisis yang digunakan dalam penelitian ini adalah statistik deskriptif dan verifikatif. Uji Regresi Berganda menggunakan bantuan program SPSS versi 20. Hasil penelitian menunjukkan bahwa kualitas produk dan layanan secara bersama-sama berpengaruh terhadap ekuitas pelanggan, hal ini dikarenakan kualitas produk dan layanan bagi jasa kuliner merupakan faktor penting dalam membentuk ekuitas pelanggan. Kualitas produk berpengaruh positif dan signifikan terhadap ekuitas pelanggan, dikarenakan kualitas produk dari tanggapan pelanggan terbukti berkualitas namun kualitas layanan tidak berpengaruh signifikan terhadap ekuitas pelanggan, dikarenakan gerai Coffee Toffee menggunakan konsep self service sehingga sedikit tingkat komunikasi karyawan dengan pelanggan.
\end{abstract}

Kata kunci: Kualitas Produk, Kualitas Layanan, Ekuitas Pelanggan

\section{PENDAHULUAN}

Populasi dan pertumbuhan di kota-kota besar yang padat dan produktif menjadikan banyak dibukanya coffee shop. Pasar bisnis coffee shop yang luas dan menguntungkan menjadikan banyak pengusaha masuk dalam industri bisnis coffee shop. Saat ini terdapat banyak coffee shop baik kelas lokal maupun internasional. Tidak hanya coffee shop seperti Coffee Bean,
Starbuck, Exelso, Kopi Tiam, dan Bengawan Solo Coffee saja yang bersaing di Jabodetabek, tetapi cukup banyak Coffee Shop kelas menengah seperti Anomali coffee, Cuppa Coffee yang ikut bersaing dalam industrifood \& beverages khususnya di kategori coffee shop termasuk Coffee Toffee. Banyaknya coffee shop yang hadir di kota-kota besar membuat persaingan antara coffee shop semakin ketat 
dalam usahanya untuk mencari pelanggan baru dan mempertahankan pelanggan yang sudah ada. Hal ini menuntut Coffee Toffee untuk dapat bersaing melalui kualitas produk dan pelayanan yang baik diantaranya kenyamanan dari fasilitas gerai Coffee Toffee yang harus selalu terjaga dengan baik.

Dengan demikian selayaknya pelanggan memperoleh keuntungan dan retensi masa depan yang berhubungan dengan ekuitas pelanggan. Ekuitas pelanggan (Customer Equity) pertama kali dicetuskan dalam sebuah artikel di Harvard Business Review berjudul "Manage Marketing by the Customer Equity Test" yang ditulis oleh Blattberg \& Deighton (1996). Blattberg \& Deighton (1996), mendefinisikan customer equity sebagai "the total of the discounted lifetime values summed over all of the firm's customer",(Bick, 2009). Kotler \& Keller (2012) menyatakan"customer equity is a complementary concept to brand equity that reflects the sum of lifetime values of all customers for a brand". Hal tersebut terletak pada kemampuan Coffee Toffee dalam memberikan Customer Life Time Value (CLTV) yang dapat memuaskan pelanggan sebagai mitra melalui penyampaian produk dan layanan yang berkualitas. Di samping itu juga tentang customer equity yang menjelaskan secara bersama antara manajemen nilai pelanggan, manajemen merek, dan manajemen kerelasian pelanggan. Pentingnya manajemen nilai pelanggan menyebabkan muncul konsep pemasaran yang dikenal sebagai ekuitas pelanggan. Ekuitas pelanggan sangat penting dalam menjaga sustainability gerai Coffee Toffee, karena itulah maka nilai pelanggan sepanjang hidup harus selalu terjaga.

Beberapa pelanggan yang mengurangi frekuensi pembeliannya maupun yang beralih ke coffee shop lainnnya telah menurunkan revenue, dan jika dibiarkan akan membuat gerai Coffee Toffee akan merugi dan bangkrut. Peristiwa ditutupnya 55 gerai karena bangkrut, menjadi pengalaman berharga. Oleh karena itu Coffee Toffee harus mampu mempertahankan ekuitas pelanggannya, agar Coffee Toffee dapat menjadi salah satu Coffee Shop terbesar dan terbaik di Indonesia. Saat ini mengalami Coffee Toffee kemajuan dengan ekspansi bisnis di tahun 2015 yang akan membuka 30 gerai baru dan akan menjadi pioneer Coffee Shop dari Indonesia untuk Go International yang sukses di tahun 2017.

Coffee Toffee menyebut bisnis "idealisme dalam romantisme (dunia kopi)", dalam perkembangannya, konsep kerjasama dengan pola waralaba adalah salah satu cara terbaik dalam memasarkan produk dan potensi bisnis Coffee Toffee. Dengan konsep pemasaran ini, Coffee Toffee dapat melayani dan menyediakan produk-produk berkualitas tinggi dengan harga yang terjangkau kepada seluruh pelanggan kami di Indonesia. Di tahun 2008, Coffee Toffee didaulat sebagai pemenang penghargaan ISMBEA 2008 (Indonesian Small Medium Business Enteprenur Award) di bidang 'inspiratif bisnis' serta dipercaya oleh majalah Pengusaha sebagai "Bisnis Prospektif 2007" bulan Juli 2010, Coffee Toffee telah mempunyai lebih dari 100 gerai yang tersebar di seluruh Indonesia dan dipilih sebagai salah satu trendsetter di industri kopi ritel Indonesia oleh majalah SWA.

Kualitas produk di Coffee Toffee dihasilkan dengan cara menemukan secara keseluruhan harapan pelanggan, yaitu dengan mengetahui harapan atas kualitas rasa dan standarisasi masing-masing menu yang tersedia. Kualitas jasa di Coffee Toffee dihasilkan dari mengetahui keseluruhan harapan pelanggan, yaitu mengetahui harapan atas kualitas jasa pelayanan, kecepatan, ketepatan, responsiveness dan keramahan yang diberikan karyawan terhadap pelanggan. Dari dua hal yang berkaitan dengan kualitas produk dan kualitas layanan, kemudian akan menciptakan produk dan layanan yang sesuai dengan dengan yang diharapkan pelanggan. Ketika manajemen PT Coffee Toffee Indonesia menetapkan ekuitas pelanggan sebagai faktor tertinggi untuk sustainability bisnis Coffee Toffee, maka yang menjadi fokus adalah mencari dan menemukan faktor penentu ekuitas pelanggan. Berdasarkan hal tersebut di atas maka penelitian ini bertujuan untuk mengetahui bagaimana kualitas produk dan layanan Coffee Toffee Bogor, dan bagaimana keduanya berpengaruh secara signifikan terhadap ekuitas pelanggan gerai Coffee Toffee Bogor. 


\section{KAJIAN PUSTAKA}

\section{Ekuitas Pelanggan}

Pentingnya manajemen nilai pelanggan menyebabkan munculnya konsep pemasaran yang dikenal sebagai ekuitas pelanggan. Ekuitas pelanggan mengukur nilai pelanggan tidak hanya berdasarkan profitabilitas pelanggan saat ini, tetapi juga kontribusinya jangka panjang dari waktu ke waktu. Hyun, (2009), menyatakan bahwa nilai jangka panjang perusahaan sangat ditentukan oleh nilai dari hubungan pelanggan perusahaan, yang disebut ekuitas pelanggan. Menurut Kotler dan Keller (2012) definisi ekuitas pelanggan adalah 'a deeply held commitment to rebuy or repatronize a preferred product or service in future despite situasional influences and marketing efforts having the potential to cause switching behavior. Jadi ekuitas adalah sebuah komitmen teguh untuk membeli kembali atau berlangganan sebuah produk atau jasa yang disukai di masa depan meskipun pengaruh situasional dan upaya pemasaran memiliki potensi dapat menyebabkan pelanggan beralih.

Ekuitas pelanggan adalah nilai bersih sekarang dari arus keuntungan masa depan dari semua nasabah (Bick, 2009). Nilai pelanggan seumur hidup atau Customer Life Time Value (CLTV), didefinisikan sebagai aliran jumlah pendapatan masa depan yang berasal dari akuisisi, retensi, dan proyeksi ekspansi, dan biaya yang terkait. Akuisisi dipengaruhi oleh sejumlah prospek, probabilitas akuisisi dari suatu prospek, dan pengeluaran akuisisi per prospek (Kotler dan Keller, 2012). Setiap pelanggan baru harus dibuat menjadi kandidat yang memungkinan untuk menjadi pelanggan yang retensi, dan add-onselling dengan cara yang menguntungkan (Roofthooft, 2009).

Kualitas pelayanan merupakan prediktor yang kuat dari kepuasan pelanggan, maka terdapat hubungan yang signifikan antara kualitas pelayanan dan kepuasan pelanggan, (Naeemet al., 2009). Loyalitas pelanggan menurut Hartono (2013), diukur lewat tiga indikator yaitu word of mouth, repurchase intention, price insensitivy. Dimensi kualitas (kualitas lingkungan fisik, kualitasmakanan, dan kualitas layanan) memiliki efekpositif dan signifikan terhadap citra mental pelanggandan berkaitan dengan restoran dan nilai yang dirasakan pelanggan. Efek dari gambaran mental pelanggan pada nilai yang dirasakan adalah positif dan signifikan (Haery, 2014). Dalam bisnis restoran, pelanggan yang puasakan kembali dan memberikan word of mouth. Restoran menghasilkan pola pengulangan pembelian dengan enam atribut yang signifikan yaitu kualitas makanan, kualitas pelayanan, konsistensi makanan dan pelayanan, berbagai menu, hubungan biaya/harga-nilai, atmosfer/suasana, dankebersihan (Josiam, 2014). Manfaat relasional mempengaruhi loyalitas pelanggan, dan kepuasan pelanggan dengan karyawan mempengaruhi loyalitas pelanggan, dampak yang sebagian dimediasi oleh kepuasan karyawan (Liu and Huang, 2014).

Selanjutnya studi Hazra (2009) menunjukkan bahwa bank-bank sektor publik juga harus maju dan mencoba yang terbaik untuk memberikan kualitas layanan yang lebih baik untuk memenangkan kembali loyalitasdan komitmen pelanggan mereka. Nasabah bank swasta lebih berkomitmen dan setia karena mereka menerima kualitas layanan yang lebih baik, sehingga kualitas pelayanan berhubungan positif dengan loyalitas pelanggan. Hyun (2009) menyatakan dalam penelitiannya bahwa ekuitas merek berpengaruh positif terhadap ekuitas pelanggan, dan ekuitas hubungan positif pengaruh ekuitas pelanggan, Nilai ekuitas berpengaruh positif terhadap ekuitas pelanggan, ekuitas merek berpengaruh positif terhadap ekuitas pelanggan, dan ekuitas hubungan berpengaruh positif terhadap ekuitas pelanggan. Skiera et al. (2011) dalam penelitiannya menunjukkan bahwa nilai pelanggan yang tinggi memiliki basis pelanggan yang kuat. Sebaliknya, Customer Equity Sustainability Ratio/CESR menunjukkan apakah perusahaan mengejar penciptaan nilai jangka panjang atau realisasi keuntungan jangka pendek. Braun (2011), melihat beberapa penyebab peralihan pelanggan adalah kegiatan pengembalian ekonomi dalam pengelolaan retensi nasabah, dan tergantung pada variasi karakteristik pelanggan dan kepemilikan pelanggan terhadap perusahaan, serta taktik spesifik yang dipilih oleh perusahaan. Liu dan Huang (2014) dalam 
penelitiannya menyatakan bahwa manfaat relasional adalah mempengaruhi loyalitas pelanggan, dan kepuasan pelanggan dengan karyawan mempengaruhi loyalitas pelanggan. Berdasarkan kajian teori di atas maka terbentuk hipotesis sebagai berikut:

H1: Kualitas produk dan kualitas layanan secara simultan mempunyai pengaruh yang positif dan signifikan terhadap ekuitas pelanggan.

\section{Kualitas Produk dan Jasa}

Kualitas dijelaskan dalam American Society for Quality (2010); Jay dan Barry (2011) merupakan keseluruhan fitur dan karakteristik produk atau jasa yang mampu memuaskan kebutuhan yang tampak atau samar. Sedangkan menurut Perreault et al. (2009) mengartikan kualitas 'From a marketing perspective, quality means a product's ability to satisfy a customer's need or requirement'. Dari sudut pandang marketing, kualitas adalah kemampuan produk untuk memuaskan kebutuhan konsumen. Schiffman and Kanuk (2010) mengatakan 'Consumers perceived quality of a product (or service) is based on variety of informational cues that they associate with the product'. Maka kualitas yang dipersepsikan konsumen terhadap suatu produk (atau jasa) didasarkan pada berbagai informasi yang mereka kaitkan dengan produk.

Tjiptono (2012); Tjiptono dan Chandra (2011) menjelaskan delapan dimensi kualitas yang dapat digunakan sebagai kerangka perencanaan dan analisis strategis. Dan delapan dimensi tersebut digunakan pada produk mobil: (1) Kinerja (performance) karakteristik operasi pokok dari produk inti yang dibeli, misalnya kecepatan, konsumsi bahan bakar, jumlah penumpang yang dapat di angkut, kemudahan dan kenyamanan dalam mengemudi, (2) Fitur atau ciri-ciri tambahan (features), yaitu karakteristik sekunder atau pelengkap, misalnya kelengkapan interior dan eksterior seperti dash board, AC, sound system dan sebagainya, (3) Reliabilitas (reliabitlity), yaitu kemungkinan kecil akan mengalami kerusakan atau gagal pakai, misalnya mobil tidak sering mogok, (4) Kesesuaian dengan spesifikasi (conformance to specification), yaitu sejauh mana karakteristik desain dan operasi memenuhi standar-standar yang telah ditetapkan sebelumnya. Misalnya standar keamanan dan emisi terpenuhi, seperti ukuran as roda untuk truk tentunya harus lebih besar daripada mobil sedan, (4) Daya tahan (durability), berkaitan dengan berapa lama produk tersebut dapat terus digunakan, (5) Serviceability, meliputi kecepatan, kompetensi, kenyamanan, kemudahan direparasi, serta penanganan keluhan secara memuaskan, (6) Estetika, yaitu daya tarik produk terhadap panca indera, misalnya bentuk fisik mobil yang menarik, warna dan sebagainya, (7) Kualitas yang dipersepsikan (perceived quality), yaitu citra dan reputasi produk serta tanggung jawab perusahaan terhadapanya. Biasanya karena kurangnya pengetahuan pembeli akan atribut atau fitur produk yang akan dibeli, maka pembeli mempersepsikan kualitasnya dari aspek harga, nama merek, iklan dan sebagainya.

Kualitas pelayanan yang dirasakan adalah penilaian keseluruhan layanan yang memberikan kontribusi untuk kepuasan pelanggan, niat pembelian, dan kinerja perusahaan (Cronin dan Taylor, 1992; Zeithaml, et al., 1996). Menurut Hasan (2013: 502), sekarang setiap produk (apapun produknya) disertai dengan unsur layanan, baik itu jasa sebagai produk inti (jasa murni) maupun layanan sebagai pelengkap. Sementara itu, Hoffman dan Bateson (2011) mengatakan 'service quality is an attitude formed by long term, overall evaluation of a firm's performance'. Jadi kualitas layanan adalah suatu sikap yang dibentuk oleh evaluasi jangka panjang secara keseluruhan pada kinerja perusahaan.

Terdapat 5 (lima) dimensi utama kualitas dalam kasus pemasaran jasa yang paling sering di jadikan acuan Tjiptono (2012); Tjiptono dan Chandra (2011): (1) reliabilitas (reliability), yakni kemampuan memberikan layanan yang di janjikan dengan segera, akurat, dan memuaskan, (2) responsivitas (responsiveness), yaitu keinginan dan kesediaan para karyawan untuk membantu para pelanggan dan memeberikan layanan dengan tanggap, (3) jaminan (assurance), mencakup pengetahuan, kompetensi, kesopanan, dan sifat dapat dipercaya yang dimiliki para karyawan, bebas dari bahaya fisik, resiko atau keragu-raguan, (4) 
empati (empathy), meliputi kemudahan dalam menjamin hubungan, komunikasi yang efektif, perhatian personal, dan pemahaman atas kebutuhan individual para pelanggan, (5) bukti fisik (tangibles), meliputi fasilitas fisik, perlengkapan, karyawan, dan sarana komunikasi.

Pentingnya berbagai dimensi SERVQUAL berkaitan dengan jarak kekuasaan dan individualisme pada dimensi budaya. Konsumen pada jarak kekuasaan rendah mengharapkan layanan yang sangat responsif dan dapat diandalkan. Pelanggan dengan jarak dengan kekuasaan tinggi menginginkan pentingnya atribut layanan yang nyata. Konsumen yang tinggi pada individualisme mengharapkan empati dan jaminan yang lebih rendah dari penyedia layanan, Dashdan Acharya (2009). Kualitas Restoran (lingkungan fisik, makanan danjasa) memiliki efekpositif pada nilai yang dirasakan pelanggan. Gambaran mental dari restoran memiliki efek positif pada nilai yang dirasakan dan kepuasan pelanggan, nilai yang dirasakan pelanggan memilik iefek positif pada kepuasan pelanggan dan kepuasan pelanggan memiliki dampak positif pada niat perilaku (Koshki et al., 2014). Tambahan dalam kehandalan (dimensi kualitas layanan) membuat perbedaan komitmen dan kemauan pelanggan untuk membayar, sedangkan peningkatan keamanan (dimensi kualitas layanan) membuat perbedaan loyalitas kepada perusahaan (Hazradan Srivastava, 2009). Kepuasan mahasiswa terhadap kualitas layanan yang diterima diukur dari segi penampilan fasilitas, peralatan, staf dan komunikasi fisik dengan menggunakan model SERVQUAL. Terdapat perubahan yang signifikan dalam tingkat kualitas pelayanan pada usia pelanggan, pendidikan dan lamanya menabung, empati dan bukti fisik adalah dimensi yang paling penting (Hussein et al., 2003). kepuasan pelanggan memainkan peran sebagai mediator dari kualitas pelayanan terhadap loyalitas layanan (Mosahab,2010).

Hasil penelitian menunjukkan bahwa persepsi tentang tangibility layanan, serta keseluruhan tingkat kepuasan pelayanan yang diterima sedikit di atas rata-rata (Hefer, 2014). Pendorong ekuitas pelanggan (nilai, merek, dan hubungan) dapat dikombinasikan dengan kualitas pelayanan (SERVQUAL) (Rosenbaumand dan Wong, 2009). Untuk mengukur respon pelanggan yang sesuai dengan tingkat intensitas, tanggapan pelanggan telah dibagi menjadi kategori: mereka yang puas dengan mekanisme kualitas dan mereka yang tidak senang (Iqbal, 2014).

Adanya kualitaslayanan yang tinggi menyebab kan nilai unggul yang dirasakan, kepuasan pelanggan, dan persepsi yang menguntungkan bagi citra perusahaan. Nilai pelanggan dirasakan juga ditemukan untuk mempengaruhi kepuasan pelanggan, citra hotel, dan pelanggan mungkin lebih untuk memilih organisasi dan merekomendasikan hal ini kepada orang lain (Hu et al.,2009). Kualitas pelayanan toko memiliki efek positif yang dapat meningkatkan persepsi konsumen terhadap citra private label brand ( $\mathrm{Wu}$, et al., 2011). Hasil kepuasan dalam pemulihan layanan merupakan hasil perilaku yang terdiri dari word of mouth, loyalitas pelanggan dan kepercayaan (Piarala et al., 2014). Kualitas layanan disediakan perusahaan memainkan peran penting dalam menghasilkan dan mempertahankan loyalitas perilaku pelanggan mereka dalam jangka panjang dan penting untuk keberlanjutan usaha (Moisescu dan Gica, 2014). Berdasarkan kajian teori di atas maka terbentuk hipotesis sebagai berikut:

H2: Kualitas produk mempunyai pengaruh yang positif dan signifikan terhadap ekuitas pelanggan.

H3: Kualits layanan mempunyai pengaruh yang positif dan signifikan terhdap ekuitas pelanggan.

\section{Kerangka Pemikiran}

Kerangka berpikir yang baik akan menjelaskan secara teoritis pertautan antara variabel yang akan diteliti. Jadi secara teoritis perlu dapat dijelaskan hubungan antar variabel independen dan dependen. Pertautan antar variabel tersebut, selanjutnya dirumuskan kedalam bentuk paradigma penelitian dan harus didasarkan pada kerangka berfikir. Kerangka pemikiran yang digunakan dalam penelitian dapat dilihat pada gambar di bawah ini: 


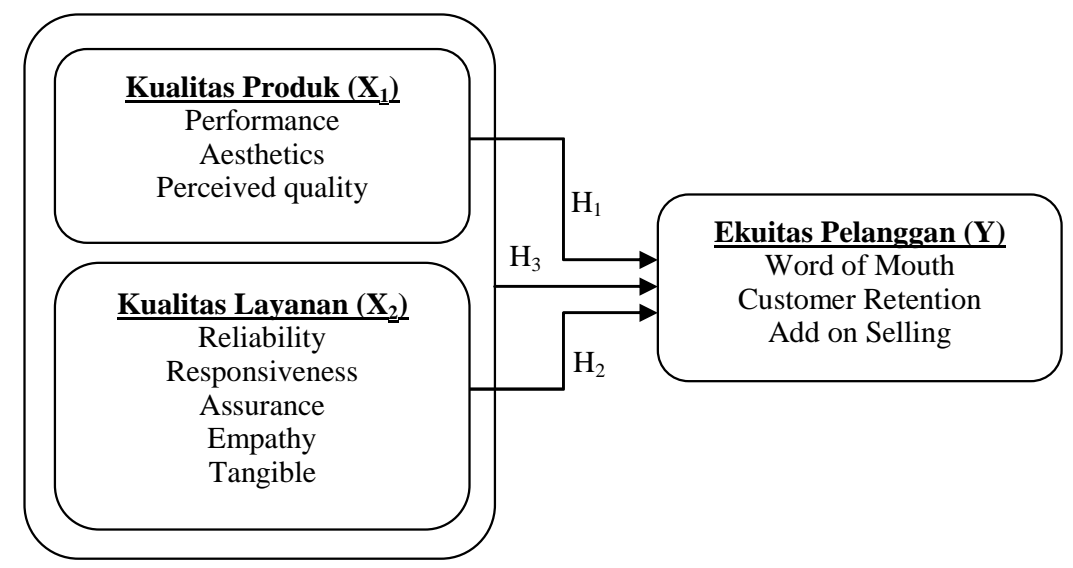

Gambar 1. Kerangka Pemikiran

\section{METODE PENELITIAN}

Jenis metode penelitian yang digunakan dalam penelitian ini adalah metodologi penelitian kuantitatif dengan memakai metode studi kasus, analisisnya dengan metode deskriptif verifikatif.

\section{Populasi dan Sampel}

Pelanggan Coffee Toffee di Bogor dengan populasi tidak terhitung, maka di ambil populasi contoh (frame Sampling) sebanyak 1.000 pelanggan untuk kemudian di ambil dengan memakai rumus Slovin dengan hasil sebanyak 90,91 pelanggan dan di bulatkan menjadi 91 pelanggan (responden), menggunakan simple random sampling. Sumber data diperoleh dari lokasi penelitian, yaitu pelanggan digerai Coffee Toffee Bogor, sedangkan sifat data yang dikumpulkan adalah data primer. Data primer merupakan data dari pelanggan dan yang digali dalam penelitian ini berasal dari pelanggan yang pernah menikmati restaurant Coffee Toffee di Bogor.

\section{Variabel Pengukuran}

Tabel 1: Operasionalisasi Variabel

\begin{tabular}{|c|c|c|c|}
\hline Variabel & Konsep & Dimensi & Indikator \\
\hline $\begin{array}{l}\text { 1. Kualitas Produk } \\
\text { (X1) }\end{array}$ & $\begin{array}{l}\text { Dari Sudut Pandang marketing, } \\
\text { kualitas adalah kemampuan pro- } \\
\text { duk untuk memuaskan kebutuhan } \\
\text { konsumen (Perreau et al, 2009: } \\
\text { 232). }\end{array}$ & $\begin{array}{l}\text { 1. Performances } \\
\text { 2. Estestika } \\
\text { 3. Perceived Quality }\end{array}$ & $\begin{array}{l}\text { 1. Rasa } \\
\text { 2. Aroma } \\
\text { 1. Tampilan } \\
\text { 2. Topping } \\
\text { 1. Harapan rasa } \\
\text { 2. Harapan Aroma }\end{array}$ \\
\hline $\begin{array}{l}\text { 2. Kualitas } \\
\text { Layanan (X2) }\end{array}$ & $\begin{array}{l}\text { Kualitas Layanan adalah suatu } \\
\text { sikap yang dibentuk oleh evaluasi } \\
\text { jangka panjang secara } \\
\text { keseluruhan kinerja perusahaan } \\
\text { (Bateson dan Hoffman, } \\
\text { 2008:325). }\end{array}$ & $\begin{array}{l}\text { 1. Reliability } \\
\text { 2. Responsiveness } \\
\text { 3. Emphaty } \\
\text { 4. Assurance } \\
\text { 5. Tangible }\end{array}$ & $\begin{array}{l}\text { 1. Kehandalan } \\
\text { 2. Akurat } \\
\text { 1. Ketanggapan } \\
\text { 1. Perhatian } \\
\text { 2. Sikap } \\
\text { 1. Terjamin } \\
\text { 2. Terpercaya } \\
\text { 1. Fasilitas } \\
\text { 2. Kerapihan }\end{array}$ \\
\hline $\begin{array}{l}\text { 3. Loyalitas } \\
\text { Pelanggan (Y) }\end{array}$ & $\begin{array}{l}\text { Kotler and Keller, (2012), 'a } \\
\text { deeply held commitment to rebuy } \\
\text { or repatronize a preferred product } \\
\text { or service in future despite situa- } \\
\text { sional influences and marketing } \\
\text { efforts having the potential to } \\
\text { cause switching behavior. }\end{array}$ & $\begin{array}{l}\text { 1. Word of Mouth } \\
\text { 2. Customer Retention } \\
\text { 3. Add on Selling }\end{array}$ & $\begin{array}{l}\text { 1. Menceritakan } \\
\text { 2. Merekomendasikan } \\
\text { 1. Datang kembali } \\
\text { 2. Yakin bertahan lama } \\
\text { 1. Membeli lebih banyak } \\
\text { 2. Peningkatan intensitas } \\
\text { terhadap produk }\end{array}$ \\
\hline
\end{tabular}




\section{Teknik Analisis Data}

Analisis regresi berganda digunakan untuk mengetahui besarnya hubungan dan pengaruh variabel independen $\left(\mathrm{X}_{1}\right.$ dan $\left.\mathrm{X}_{2}\right)$ terhadap variabel dependen $(\mathrm{Y})$. untuk memperoleh hasil yang lebih terarah, maka penulis menggunakan bantuan program SPSS (statistical product and service solution) versi 20.00 .

\section{ANALISIS DATA DAN DISKUSI}

\section{Hasil Uji Validitas}

Valid berarti instrument tersebut dapat digunakan untuk mengukur apa yang seharusnya diukur. Uji validitas dilakukan dengan cara menggunakan product momment, hasil perolehannya adalah seluruh butir pernyataan adalah valid karena $r$ test lebih besar dari pada $r$ table.

\section{Hasil Uji Reliabilitas}

Hasil pengujian reliabilitas instrumen menunjukkan nilai alpha cronbach masing masing variabel sebesar 0,887 variabel kualitas produk (X1), variabel kualitas layanan (X2) sebesar 0,869 dan variabel ekuitas pelanggan (Y) sebesar 0,849 , sehingga dapat disimpulkan nilai lebih besar dari 0,80, maka seluruh butir pernyataan dapat dinyatakan reliabel dengan kriteria tersebut dan dapat digunakan pada penelitian.

\section{ANALISIS DATA}

\section{Pengujian Signifikasi}

\section{Hipotesis Pertama}

Uji $F$ digunakan untuk menguji ada tidaknya pengaruh variable-variabel independen terhadap variable dependent secara simultan (bersama-sama). Hasil uji F dapat dilihat pada tabel 2 dikaitkan dengan hipotesis yang diajukan.

Berdasarkan hasil uji simultan pada Tabel 2 diperoleh nilai probabilitas (Sig) adalah $0.000<0.05$ jadi dapat disimpulkan bahwa terdapat pengaruh yang signifikan pada variable independent (kualitas produk dan kualitas layanan) secara simultan terhadap variabel dependent (ekuitas pelanggan). Atau dengan cara lain yaitu dengan membandingkan nilai $\mathrm{F}$ hitung dengan $\mathrm{F}$ tabel dilihat dari signifikansi $\alpha$ 5\%. Berdasarkan hasil uji $\mathrm{F}$ diperoleh nilai $\mathrm{F}$ hitung sebesar 35.398 sedangkan berdasarkan $\mathrm{F}$ tabel nilai $\mathrm{F}$ sebesar 3.10 (35.398> 3.10). Oleh karena $\mathrm{F}$ hitung > $\mathrm{F}$ tabel maka $\mathrm{H} 0$ ditolak, artinya variabel independent (kualitas produk dan kualitas layanan) secara bersama-sama berpengaruh secara signifikan terhadap variabel dependen (ekuitas pelanggan). Dari hasil uji $\mathrm{F}$ (simultan), nilai $\mathrm{F}$ hitung $>\mathrm{F}$ tabel dan nilai signifikansinya kurang 0.05 menunjukan bahwa variabel kualitas produk dan kualitas layanan secara simultan mempunyai pengaruh yang signifikan terhadap ekuitas pelanggan.

Tabel 2: Hasil Uji F (Simultan)

\begin{tabular}{rlrrrrr}
\multicolumn{7}{c}{ ANOVA $^{\mathbf{a}}$} \\
\hline & Model & Sum of Squares & \multicolumn{1}{c}{ Df } & Mean Square & F & Sig. \\
\hline \multirow{3}{*}{1} & Regression & 7.840 & 2 & 3.920 & 35.398 & $.000^{\mathbf{b}}$ \\
& Residual & 9.745 & 88 & .111 & & \\
& Total & 17.584 & 90 & & & \\
\hline
\end{tabular}

a. Dependent Variable: ekuitas pelanggan

b. Predictors: (Constant), kualitas layanan, kualitas produk

Sumber: data diolah, 2014

Tabel 3: Hasil Uji t

\begin{tabular}{|c|c|c|c|c|c|}
\hline \multicolumn{6}{|c|}{ Coefficients $^{\mathrm{a}}$} \\
\hline \multirow[t]{2}{*}{ Model } & \multicolumn{2}{|c|}{ Unstandardized Coefficients } & $\begin{array}{l}\text { Standardized } \\
\text { Coefficients }\end{array}$ & $\mathrm{t}$ & Sig. \\
\hline & B & Std. Error & Beta & & \\
\hline (Constant) & .708 & .418 & & 1.695 & .094 \\
\hline kualitas produk & .596 & .108 & .559 & 5.504 & .000 \\
\hline kualitaslayanan & .180 & .117 & 156 & 1.535 & .128 \\
\hline
\end{tabular}

a. Dependent Variable: ekuitas pelanggan

Sumber: data diolah, 2014 
Dari tabel 3 uji $\mathrm{t}$ dapat diuraikan sebagai berikut: persamaan regresi : $\mathrm{Y}=0.708$ $+0.596\left(\mathrm{X}_{1}\right)+0.180\left(\mathrm{X}_{2}\right)+$ e. Interprestasi untuk masing-masing independen: $\mathrm{a}=0.708$, konstanta sebesar 0.708 berarti jika kualitas produk dan layanan dikontrol konstan, maka nilai ekuitas pelanggan akan tetap sebesar 0.708. B1=0.596. Koefesien regresi $\mathrm{X}_{1}$ sebesar 0.596 menyatakan setiap peningkatan kualitas produk sebesar satu unit maka ekuitas pelanggan akan mengalami peningkatan sebesar 0.596. B2=0.180. Koefisien regresi $\mathrm{X}_{2}$ sebesar 0.180 menyatakan setiap peningkatan kualitas layanan sebesar satu unit maka ekuitas pelanggan akan mengalami peningkatan sebesar 0.180.

\section{Hipotesis Kedua}

Jika statistik t hitung <statistic $\mathrm{t}$ tabel dan sig > 0.05 maka koefesien regresi tidak berpengaruh signifikan. Jika statistic $\mathrm{t}$ hitung $>$ statistic $\mathrm{t}$ tabel dan sig $<0.05$, maka koefesien regresi signifikan. Berdasarkan tabel 3 di atas, koefesien regresi kualitas produk sebesar 0.596 menunjukan bahwa variable kualitas produk $\left(\mathrm{X}_{1}\right)$ berpengaruh positif terhadap ekuitas pelanggan (Y). Nilai t hitung variabel kualitas produk $\left(\mathrm{X}_{1}\right)$ adalah 2.096 dan $\mathrm{t}$ tabel dengan uji dilakukan satu sisi pada $\alpha 5 \%$ bernilai 1.662 sehingga $\mathrm{t}$ hitung $>\mathrm{t}$ tabel $(5.504>1.662)$ dan nilai signifikansinya lebih kecil dari 0.05 yaitu $(0.00<0.05)$ maka dapat disimpulkan bahwa variabel kualitas produk berpengaruh secara signifikan terhadap ekuitas pelanggan. Nilai $\mathrm{t}$ pada variabel kualitas produk $\left(\mathrm{X}_{1}\right)$ sebesar 5.504 menunjukan bahwa variabel kualitas produk terbukti berpengaruh positif terhadap ekuitas pelanggan. Pengaruh kualitas produk terhadap ekuitas pelanggan adalah signifikan karena hasil uji t (parsial) $\mathrm{t}$ hitung $>\mathrm{t}$ tabel dan nilai signifikansinya lebih kecil dari 0.05 .

\section{Hipotesis Ketiga}

Jika statistik $\mathrm{t}$ hitung $<\mathrm{t}$ tabel dan sig $>0.05$ maka koefisien regresi tidak signifikan. Jika statistic $\mathrm{t}$ hitung $>\mathrm{t}$ tabel dan sig $<0.05$ maka koefisien regresi berpengaruh signifikan. Berdasarkan Tabel 2, koefisien regresi kualitas layanan sebesar 0.180 menunjukkan bahwa variable kualitas layanan $\left(\mathrm{X}_{2}\right)$ tidak berpengaruh terhadap ekuitas pelanggan (Y). Nilai t hitung variabel kualitas layanan $\left(\mathrm{X}_{2}\right)$ adalah 1.535 dan t tabel dengan uji dilakukan satu sisi pada $\alpha 5 \%$ bernilai 1.66235 sehingga $\mathrm{t}$ hitung $>\mathrm{t}$ tabel (1.535 <1662) dan nilai signifikansinya lebih besar dari 0.05 yaitu $0.128(0.128>0.05)$ maka dapat disimpulkan bahwa variabel kualitas layanantidak berpengaruh secara signifikan terhadap ekuitas pelanggan. Nilai t pada variabel kualiltas layanan $\left(\mathrm{X}_{2}\right)$ sebesar 1.535 menunjukan bahwa variabel kualitas layanan terbukti tidak berpengaruh terhadap ekuitas pelangggan. Pengaruh kualitas layanan terhadap ekuitas pelanggan adalah tidak signifikan karena hasil uji $\mathrm{t}$ (parsial) $\mathrm{t}$ hitung $<\mathrm{t}$ tabel dan nilai signifikansinya lebih besar dari 0.05 .

\section{Uji Koefisien Determinasi}

Berdasarkan tabel 4, angka $\mathrm{R}$ square adalah 0.446 hal ini berarti $44.6 \%$ ekuitas pelanggan (Y) dapat dijelaskan oleh variabel-variabel independen kualitas produk dan kualitas layanan. Sedangkan sisanya $(100 \%-44.6 \%=$ $53.4 \%$ ) adalah $53.4 \%$ dijelaskan oleh faktor lain yang tidak dimasukkan dalam penelitian ini.

\section{Diskusi}

Coffee Toffee menerapkan visinya 'Go Local All The Way'akan menjadi merk yang dicintai oleh pelanggan dimanapun di belahan dunia, dengan perpaduan antara kualitas terbaik dan harga terjangkau yang akan dicari oleh pelanggan, dan dengan pelayanan hangatakan dirindukan setiap saat. Pelanggan Coffee Toffee sebagai unit analisis dalam penelitian ini adalah 40 orang $(44 \%)$ yang berjenis kelamin pria, dan 51 orang $(56 \%)$ berjenis kelamin wanita dan memiliki latar belakang dengan status pelajar sebanyak 22 orang (24,2\%), mahasiswa/mahasiswi sebanyak 25 orang $(27,5 \%)$, pegawai/karyawan sebanyak 34 orang $(37,4 \%)$, pengusaha/wiraswasta sebanyak 7 orang $(7,7 \%)$ dan sisanya status lain-lain sebanyak 3 orang $(3,3 \%)$. Usia pelanggan $14-$ 20 tahun sebanyak 34 orang $(37,4 \%)$, usia 21 30 tahun sebanyak 52 orang $(57,1 \%)$, usia 31 40 tahun sebanyak 4 orang $(4,4 \%)$ dan usia > 40 tahun sebanyak 1 orang $(1,1 \%)$. 
Tabel 4: Hasil Uji Koefisien Determinasi

\begin{tabular}{|c|c|c|c|c|}
\hline \multicolumn{5}{|c|}{ Model Summary $^{b}$} \\
\hline Model & $\mathrm{R}$ & R Square & $\begin{array}{l}\text { Adjusted R } \\
\text { Square }\end{array}$ & $\begin{array}{l}\text { Std. Error of the } \\
\text { Estimate }\end{array}$ \\
\hline 1 & $.668^{\mathrm{a}}$ & .446 & .433 & .3327668 \\
\hline
\end{tabular}

Berikutnya dijelaskan analisis deskriptif pada variabel independen penelitian yaitu kualitas produk dan layanan, tanggapan pelanggan tentang "Produk minuman di Coffee Toffee berkualitas" mendapatkan skor rata-rata (mean) terbaik yaitu 4.40 dan harus dipertahankan, namun ada nilai descriptive statistik dari tanggapan pelanggan yang sebaiknya ditingkatkan yaitu pernyataan "design gelas take away (dibawa pulang) di Coffee Toffee simple dan sesuai kegunaan" yang mendapatkan skor rata-rata (mean) 3.91. Hasil ini sesuai dengan teori menurut Tjiptono (2012) menjelaskan bahwa kualitas apabila dikelola dengan tepat, kontribusi positif terhadap terwujudnya kepuasan dan loyalitas pelanggan. Kualitas memberikan nilai plus berupa motivasi para pelanggan untuk menjalin ikatan relasi saling menguntungkan dalam jangka panjang dengan perusahaan. Tangapan pelanggan "Karyawan Coffee Toffee selalu bersikap sopan dalam pelayanan" mendapatkan skor rata-rata (mean) terbaik yaitu 4.41 dan harus dipertahankan, namun ada nilai descriptive statistik dari tanggapan pelanggan yang sebaiknya ditingkatkan yaitu pernyataan "Gerai Coffee Toffee memiliki fasilitas toilet yang bersih" yang mendapatkan skor rata-rata (mean) 3.73.

Pada variabel dependen ekuitas pelanggan, tanggapan pelanggan "Saya bersedia datang kembali ke gerai Coffee Toffe" mendapatkan skor rata-rata (mean) terbaik yaitu 4.58 dan harus dipertahankan, namun ada beberapa nilai descriptive statistik dari tanggapan pelanggan yang sebaiknya ditingkatkan yaitu pernyataan "Saya tetap datang ke gerai Coffee Toffee, saat ada pilihan tawaran dari coffee shop/kedai kopi yang lain" yang mendapatkan skor rata-rata (mean) 3.87, tanggapan pelanggan"Saya bersedia membeli produk Coffee Toffee sedikit lebih mahal dari harga yang ada sekarang" yang mendapatkan skor rata-rata (mean) 3.31, dan tanggapan pelanggan "Produk coffee toffee tetap pilihan utama" yang mendapat skor rata-rata (mean) 3.88. Hal tersebut selaras dengan teori Lovelockdan Wirtz (2011) yaitu loyalitas pelanggan adalah kesediaan pelanggan untuk terus membeli dari suatu perusahaan dalam jangka panjang dan merekomendasikan produk kepada teman dan rekan, termasuk preferensi, keinginan dan niat masa depan dan juga, loyalitas didefinisikan sebagai tingkah laku dan niat untuk berlangganan, (Peter dan Olson, 2010). Roofthooft (2009) dalam penelitiannya menyatakan bahwa setiap pelanggan baru harus dibuat menjadi kandidat yang memungkinan untuk menjadi pelanggan yang retensi, dan add-onselling dengan cara yang menguntungkan.

H1: Kualitas produk dan kualitas layanan secara simultan mempunyai pengaruh yang positif dan signifikan terhadap ekuitas pelanggan.

Hipotesis pertama menunjukkan kualitas produk dan layanan berpengaruh terhadap ekuitas pelanggan. Pelanggan Coffe Toffe memiliki keyakinan bahwa produk dan layanan yang diberikan dapat diinformasikan dan direkomendasikan ke teman dan sahabat. Pelanggan juga bersedia untuk bertahan dalam jangka waktu lama untuk mengunjungi gerai Coffee Toffee dan menambah jumlah pembeliannya. Hal ini searah dengan Hasan (2013), kualitas produk berhubungan kuat dengan kesetiaan pelanggan. Kualitas meningkatkan penjualan dan meningkatkan penguasaan pasar, dan mengarahkan konsumen kearah kesetiaan. Sementara itu, Tjiptono (2012) menjelaskan bahwa kualitas apabila dikelola dengan tepat, berkontribusi positif terhadap terwujudnya kepuasan dan kepuasan pelanggan. Kualitas memberikan nilai plus berupa motivasi para pelanggan untuk menjalin ikatan relasi saling 
menguntungkan dalam jangka panjang dengan perusahaan. Dari hasil penelitian sebelumnya Hyun (2009), meneliti adanya ekuitas hubungan memiliki dampak kuat pada ekuitas pelanggan. Piaralaet al., (2014) menyatakan dalam temuannya bahwa hasil kepuasan dalam pemulihan layanan merupakan hasil perilaku yang terdiri dari word of mouth, loyalitas pelanggan dan kepercayaan.

Koefisien determinan $44.6 \%$ menununjukkan ekuitas pelanggan Coffee Toffee dapat dijelaskan oleh kualitas produk dan kualitas layanan. Sedangkan 53.4\% dijelaskan oleh faktor lain yang tidak dimasukkan dalam penelitian ini. Masih banyak faktor yang dapat dibangun melalui kualitas produk dan layanan untuk mewujudkan ekuitas pelanggan jangka panjang yang menguntungkan Coffee Toffee.

$\mathrm{H} 2$ : Kualitas produk secara parsial mempunyai pengaruh yang positif dan signifikan terhadap ekuitas pelanggan.

Hipotesis kedua menunjukkan bahwa kualitas produk yang ditawarkan Coffee Toffee dapat membentuk ekuitas pelanggannya, hal ini sesuai dengan pernyataan Hasan (2013), kualitas produk berhubungan kuat dengan kesetiaan pelanggan. Kualitas meningkatkan penjualan dan meningkatkan penguasaan pasar, dan mengarahkan konsumen kearah kesetiaan. Maka kualitas yang dipersepsikan konsumen terhadap suatu produk (atau jasa) didasarkan pada berbagai informasi yang mereka kaitkan dengan produk termasuk word of mouth. Dengan demikian sesuai dengan penelitian Josiam et al. (2014) yang menghasilkan pola pengulangan pembelian dengan enam atribut yang signifikan yaitu kualitas makanan, kualitas pelayanan, konsistensi makanan dan pelayanan, berbagai menu, hubungan biaya/harga-nilai, atmosfer/suasana, dan kebersihan. Tjiptono (2012) menjelaskan bahwa kualitas apabila dikelola dengan tepat, kontribusi positif terhadap terwujudnya kepuasan dan ekuitas pelanggan. Kualitas memberikan nilai plus berupa motivasi para pelanggan untuk menjalin ikatan relasi saling menguntungkan dalam jangka panjang dengan perusahaan. Bahwa hasil penelitian kualitas layanan tidak mempunyai pengaruh yang signifikan terhadap ekuitas pelanggan. Hasil penelitian ini sesuai dan memperkuat hasil penelitian sebelumnya oleh Aryani dan Rosinta (2010); Hu (2009) yang menyatakan adanya kualitas layanan yang tinggi menyebabkan nilai unggul yang dirasakan, kepuasan pelanggan, dan persepsi yang menguntungkan bagi citra perusahaan. Pendorong ekuitas pelanggan dapat dikombinasikan dengan kualitas pelayanan (SERVQUAL) (Rosenbaum dan Wong, 2009). Coffee Toffee belum optimal dalam memberikan layanan yang berkualitas yang dapat mendorong terbentuknya ekuitas pelanggan.

H3: Kualitas produk secara parsial mempunyai pengaruh yang positif dan signifikan terhadap ekuitas pelanggan.

Hipotesis ketiga menunjukkan pengaruh kualitas layanan terhadap ekuitas pelanggan secara signifikan tidak berpengaruh. Menurut Tjiptono (2012) menjelaskan bahwa kualitas apabila dikelola dengan tepat, kontribusi positif terhadap terwujudnya kepuasan dan loyalitas pelanggan. Kualitas memberikan nilai plus berupa motivasi para pelanggan untuk menjalin ikatan relasi saling menguntungkan dalam jangka panjang dengan perusahaan. Bahwa hasil penelitian kualitas layanan tidak mempunyai pengaruh yang signifikan terhadap ekuitas pelanggan. Coffe Toffe memberikan layanan minimalis karena pelanggan melakukan self service sehingga sedikit tingkat komunikasi karyawan dengan pelanggan. Hal ini yang membuat pelanggan kuranga nyaman sehingga cenderung tidak loyal dan menyebabkan ekuitasnya tidak dapat bertahan lama. Sesuai dengan penelitian Braun (2011) yang melihat beberapa penyebab peralihan pelanggan adalah kegiatan pengembalian ekonomi dalam pengelolaan retensi nasabah, dan tergantung pada variasi karakteristik pelanggan dan kepemilikan pelanggan terhadap perusahaan, serta taktik spesifik yang dipilih oleh perusahaan. Hasil penelitian ini juga sesuai dan memperkuat hasil penelitian sebelumnya Aryani dan Rosinta (2010) menunjukkan bahwa secara parsial tidak terdapat pengaruh signifikan antara kualitas layanan terhadap loyalitas pelanggan. Hyun (2009) menyatakan bahwa nilai jangka panjang perusahaan sangat 
ditentukan oleh nilai dari hubungan pelanggan perusahaan, yang disebut ekuitas pelanggan.

\section{PENUTUP}

Kualitas produk dan layanan gerai Coffee Toffee Bogor secara simultan berpengaruh terhadap ekuitas pelanggannya, hal ini dikarenakan kualitas produk dan layanan bagi jasa kuliner merupakan faktor penting dalam membentuk ekuitas pelanggan. Kualitas produk gerai Coffee Toffee Bogor berpengaruh positif dan signifikan terhadap ekuitas pelanggannya, hal ini dikarenakan kualitas produk di Coffee Toffee Bogor dari hasil tanggapan pelanggan terbukti berkualitas. Kualitas layanan gerai Coffee Toffee Bogor tidak berpengaruh signifikan terhadap ekuitas pelanggannya, hal ini dikarenakan gerai Coffee Toffee menggunakan konsep self service sehingga tingkat komunikasi karyawan dengan pelanggan tidak banyak, jadi tidak nampak empati dan responsiveness karyawan pada pelanggan. Di samping dari dimensi tangibility masih perlu ditingkatkan fasilitas toilet Gerai Coffee Toffee yang bersih.

Gerai Coffee Toffee Bogor hendaknya mempertahankan kualitas produk. Kualitas produk minuman, aroma kopi, model cangkir/gelas, sudah sangat baik dan harus dipertahankan, meskipun untuk kualitas produk makanan/snack, topping minuman, dan desain take away glass perlu ditingkatkan lagi. Gerai Coffee Toffee Bogor harus lebih meningkatkan kinerja dari segi kualitas layanan. Kehandalan karyawan, pengetahuan karyawan, kebersihan fasilitas toilet dan kecepatan pelayanan di gerai Coffee Toffee Bogor merupakan prioritas yang harus ditingkatkan untuk mendapatkan kualitas pelayanan terbaik. Gerai Coffee Toffee Bogor hendaknya lebih memberi perhatian dan fokus terhadap pelanggan dalam menjalankan operasional gerai, serta pihak franchisor harus berhati-hati dalam menetapkan kebijakan harga. Keterbatasan sampel dapat diatasi pada penelitian lanjutnya dengan memperluas penelitian pada gerai-gelas Coffee Toffee yang tersebar di seluruh Indonesia. Karena pengaruh faktor lain terhadap ekuitas pelanggan di gerai Coffee Toffee Bogor yang tidak dimasukkan dalam penelitian ini masih relatif besar, maka disarankan untuk selanjutnya meneliti faktor- faktor yang mempengaruhi ekuitas pelanggan melalui brand image dan bauran pemasaran yaitu: price, promotion dan place.

\section{DAFTAR PUSTAKA}

American Society for Quality. 2010. Quality Cost - What and How.Milwaukee, WI : ASQC Quality Cost Committee.

Aryani, D. dan F. Rosinta. 2010. Pengaruh kualitas layanan terhadap kepuasan pelanggan dalam membentuk loyalitas pelanggan. Jurnal Ilmu Administrasi dan Organisasi, Vol 17. Hlm : 114126.

Hoffman, KD.and JEG. Bateson. 2011. Service Marketing: Concept, Strategies \& Cases. South-Western College

Bick, GNC.2009. Increasing shareholder value through building customer and brand equity. Journal of Marketing Management, Vol. 25, No. 1-2. 117-141.

Blattberg, R.C. and Deighton, J. 1996. Manage marketing by the customer equity test. Harvard Business Review,Vol. 74, No. 4, pp.136-44

Braun, M. and DA. Schweidel, 2011.Modeling customer lifetimes with multiple causes of churn.Marketing Science, Vol. 30, No. 5, pp. 881-902.

Cronin, JJ. and SA. Taylor. 1992. Measuring service quality: a examination and extension. Journal of Marketing, 56(3), $55-68$.

Dash, S, and M.Acharya.2009. The effect of power distance and individualism on service quality expectations in banking; a two-country individual- and national cultural comparison. The International Journal of Bank Marketing., Vol. 27, Ed 5; pg. 336.

Haery, FA. 2014. Studying the effect of food quality dimensions (physical environment, food and services) on mental image of the restaurant and customers' satisfaction and intentions based on Kisang's model, International Journal 
of Academic Research in Business and Social Sciences, July 2014, Vol. 4, No. 7, ISSN: 2222-6990.

Hartono, S. 2013. Riset Pemasaran dan Konsumen. Seri 3. Bogor: IPB Press.

Hasan, A. 2013. Marketing dan Kasus-Kasus Pilihan, Jakarta: CAPS (Center for Academic Publishing Service).

Hazra, SG. and KBLSrivastava ,2009.Impact of service quality on customer loyalty, commitment and trust in the Indian banking sector, IUP Journal of Marketing Management.Hyderabad, Vol. 8, Edisi 3/4; pg. 74, 22 pgs.

Hefer, Y. 2014. Measuring service quality: the student as primary consumer, International Business \& Economics Research Journal, Volume 13, Number 6.

Heizer, Jay and R. Barry. 2011. Operation Management, $10^{\text {th }}$, Pearson Education, United Kongdom.

Hu, HH.et al. 2009. Relationships and impacts of service quality, perceived value, customer satisfaction, and image: an empirical study.The Service Industries Journal, Vol. 29, No. 2, February, 111-125, DOI: 10.1080/02642060802292932.

Hussein, A, et al. 2003. Analysing service quality in the UAE Islamic Banks. Journal of Financial Services Marketing, Vol. 8, $2119-132$.

Hyun, S.S. 2009. Managing long-term customer value in the theme park industry: a customer equity-based approach. Journal of Travel and Tourism Research (Online). Kusadasi Avdin: pg. 28, 27 pgs.

Iqbal, J. 2014. Perception about Service Quality in Shifa International Hospital, Journal of Business Strategies, Vol.8, No.1, 2014, p 39-51.

Josiam, BM., et al. 2014. Assessing quality of food, service and customer experience at a restaurant: the case of a student run restaurant in the USA. Journal of Services Research, Volume 14, Number 1.

Koshki, N. et al. 2014.The study on the effects of environmental quality, food and restaurant services on mental image of the restaurant, customer perceived value, customer satisfaction and customer behavioral intentions: (case study of Boroujerd's Restaurants), Kuwait Chapter Of Arabian Journal Of Business And Management Review, Vol.3, No.10; June. 2014.

Kotler, P. and KL. Keller. 2012. Marketing Management, $14^{\text {th }}$ Global Edition, Prentice Hall International, Inc., USA.

Liu, CM. and CJ. Huang. 2014. Relational benefits, customer satisfaction, and customer loyalty in chain store restaurants. The International Journal of Organizational Innovation, Vol 7 Num 1 July 2014.

Lovelock, C.H. and J. Wirtz. 2011. Essential of Service Marketing. Singapore: Prentice Hall.

Moisescu,O.I. \& Gica, O.A.2014. The impact of service quality on customer behavioral loyalty in the case of travel agencies from Romania.Amfiteatru Economic, JEL Classification: M31; L83, Vol. XVI, Special No. 8.

Mosahab, R. 2010. Service quality, customer satisfaction and loyalty: a test of mediation. International Business Research, Vol. 3, No. 4.

Naeem,H. et al. 2009. Service quality and its impact on customer satisfaction: an empirical evidence from the Pakistani banking sector. The International Business \& Economics Research Journal.Littleton, Vol. 8, Edisi 12; pg. 99.

Perreault, WD. et al. 2009. Basic marketing a marketing strategy planning approach international edition, New York: Mc Graw - Hill. 
Peter, JP. and JC. Olson. 2010. Consumer behavior \& marketing strategy. Ninth Edition, Mc Graw-Hill Irwin, New York.

Piarala, NK. et al. 2014. Antecedent and outcomes of satisfaction with service recovery: a study among mobile phone users in central region of Malaysia. Asian Social Science; Vol. 10, No. 12; Vol. 19, Edisi 1; pg. 30.

Roofthooft, W.2009.Customer equity: a creative tool for smesin the services industry, Springer-Verlag p 37-48.

Rosenbaum, MS. and IA. Wong. 2009. Modeling customer equity, SERVQUAL, and ethnocentrism: a Vietnamese case study. Journal of Service Management, Vol. 20 No. 5, p. 544-560.

Schiffman GL. And LL. Kanuk, 2010. Consumer Behavior. Tenth Edition, New Jersey: Pearson Educational Internasional Prentice Hall, Inc.
Skiera, B. et al. 2011.Customer equity sustainability ratio: a new metric for assessing a firm's future orientation. Journal of Marketing, Vol. 75, 118 131.

Tjiptono, F. 2012. Service management mewujudkan layanan prima. Yogyakarta: Andi.

Tjiptono, F. dan G. Chandra, 2011.Service, Quality \& Satisfaction. Yogyakarta: Andi.

Wu, PCS, et al. 2011. The effect of store image and service quality on brand image and purchase intention for private label brands. Australasian Marketing Journal. St. Lucia, Vol. 19, Edisi 1; pg. 30.

Zeithaml VA, et al. 1996. The behavioural consequences of service quality, Journal of Marketing Management, 60 (No. April), 31-46. 